\title{
Kinetic Analysis of Drug Release From Nanoparticles
}

\author{
Mohammad Barzegar-Jalali ${ }^{1,2}$, Khosro Adibkia ${ }^{1,2,3}$, Hadi Valizadeh ${ }^{1,4}$, Mohammad Reza Siahi Shadbad ${ }^{1}$, \\ Ali Nokhodchi ${ }^{1,5}$, Yadollah Omidi ${ }^{1,2}$, Ghobad Mohammadi ${ }^{1,6}$, Somayeh Hallaj Nezhadi ${ }^{1,7}$, Maryam \\ Hasan $^{1,7}$
}

${ }^{1}$ Faculty of Pharmacy, Tabriz University of Medical Sciences, Tabriz, Iran ${ }^{2}$ Research Center for Pharmaceutical Nanotechnology, Tabriz University of Medical Sciences, Tabriz, Iran ${ }^{3}$ School of Pharmacy, Zanjan University of Medical Sciences, Zanjan, Iran ${ }^{4}$ Biotechnology Research Center, Tabriz University of Medical Sciences, Tabriz, Iran ${ }^{5}$ Medway School of Pharmacy, Universities of Kent and Greenwich, Chatham, Kent, England, UK ${ }^{6}$ School of Pharmacy, Kermanshah University of Medical Sciences, Kermanshah, Iran ${ }^{7}$ Drug Applied Research Center, Tabriz University of Medical Sciences, Tabriz, Iran

Received, March 01, 2008; Accepted, April 20, 2008, Published April 22, 2008.

ABSTRACT- PURPOSE. Comparative drug release kinetics from nanoparticles was carried out using conventional and our novel models with the aim of finding a general model applicable to multi mechanistic release. Theoretical justification for the two best general models was also provided for the first time. METHODS. Ten conventional models and three models developed in our laboratory were applied to release data of 32 drugs from 106 nanoparticle formulations collected from literature. The accuracy of the models was assessed employing mean percent error (E) of each data set, overall mean percent error (OE) and number of Es less than 10 percent. RESULTS. Among the models the novel reciprocal powered time (RPT), Weibull (W) and log- probability (LP) ones produced OE values of $6.47,6.39$ and 6.77, respectively. The OEs of other models were higher than $10 \%$. Also the number of errors less than $10 \%$ for the models was $84.9,80.2$ and 78.3 percents of total number of data sets. CONCLUSIONS. Considering the accuracy criteria the reciprocal powered time model could be suggested as a general model for analysis of multi mechanistic drug release from nanoparticles. Also $\mathrm{W}$ and LP models were the closest to the suggested model RPT.

\section{INTRODUCTION}

Nanotechnology has been received immense attentions in various branches of science including medical and pharmaceutical sciences (1). Numerous research articles in the field of pharmaceutical nanotechnology have been appeared in literature citation. Our focus, however, is on some recently published review articles that deal with pharmaceutical nanotechnology (2-7). The drug release from pharmaceutical nanoparticles is a major determinant in its biological effect, thus evaluation of drug release kinetic is of paramount importance in the field. The use of kinetic models is often helpful in elucidating release mechanisms which in turn can be of use in the control of drug release. Another advantage of the kinetics is to represent several release data with one or two parameters. To the best of our knowledge a comprehensive kinetic representation of drug release from nanoparticles for the purpose of finding a general model has not been reported in the literature. Parameters obtained from such a general model can be employed for comparing different delivery systems of a drug as well as correlating with bioavailability data. It is obvious that the comparison and correlation cannot be made with parameters obtained from data fitting to various kinetic models. In the present work release data of 32 drugs from 106 nanoparticle formulations gathered from various research articles was analyzed using 10 well known $(8,9)$ as well as 3 models developed in our laboratory $(10,11)$. Also, a theoretical justification of the best models is provided from a general rate expression describing both the Noyes-Whitney dissolution law as well as Fick's first law of diffusion.

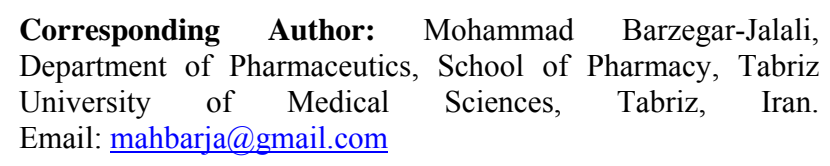




\section{METHODS}

\section{Kinetic models}

The kinetic models were those which have been used in interpretation of drug release data (8-11). The equations of the kinetic models are presented in Table 1.

\section{Data}

The release data for kinetic analysis was collected from various research articles the list of which is seen in Table 2. The name of drugs, type of nanoparticles, number of data in each set and the method of release measurement are included in the Table.

Table 1: Kinetic models used for analysis of drug nanoparticle release data and their corresponding overall mean percent errors (OE) together with their percent number of errors (NE) less than 5\%, 10\% and $12 \%$.

\begin{tabular}{|c|c|c|c|c|c|c|c|}
\hline No. & Model name ${ }^{a}$ & Model & OE & & $\mathrm{NE}<5$ & $\mathrm{NE}<10$ & $\mathrm{NE}<12$ \\
\hline 1 & Zero order & $\mathrm{F}=\mathrm{k}_{0} \mathrm{t}$ & 18.28 & & 4.7 & 34.9 & 46.2 \\
\hline 2 & First order & $\ln (1-\mathrm{F})=-\mathrm{k}_{\mathrm{f}} \mathrm{t}$ & 16.41 & & 19.8 & 46.2 & 54.7 \\
\hline 3 & Higuchi & $F=k_{H} \sqrt{t}$ & 10.65 & & 28.3 & 65.1 & 68.9 \\
\hline 4 & Power law & $\ln \mathrm{F}=\ln \mathrm{k}_{\mathrm{p}}+\mathrm{p} \ln \mathrm{t}$ & 7.66 & & 32.1 & 53.8 & 56.6 \\
\hline 5 & Hixson-Crowell & $1-\sqrt[3]{1-F}=k_{\frac{1}{3}} t$ & 26.63 & & 9.4 & 25.5 & 32.1 \\
\hline 6 & Square root of mass & $1-\sqrt{1-F}=k_{\frac{1}{2}} t$ & 16.46 & & 11.3 & 43.4 & 53.8 \\
\hline 7 & $\begin{array}{l}\text { Three seconds root of } \\
\text { mass }\end{array}$ & $1-\sqrt[3]{(1-F)^{2}}=k_{\frac{2}{3}} t$ & 17.16 & & 6.6 & 40.6 & 52.8 \\
\hline 8 & Weibull & $\ln [-\ln (1-F)]=-\beta \ln t_{d}+\beta \ln t$ & 6.39 & & 47.2 & 80.2 & 85.8 \\
\hline 9 & Linear probability & $\mathrm{Z}=\mathrm{Z}_{0}+\mathrm{qt}$ & 16.67 & & 11.3 & 40.6 & 51.9 \\
\hline 10 & Log - probability & $\mathrm{Z}=\mathrm{Z}_{0}^{\prime}+\mathrm{q}^{\prime} \operatorname{lnt}$ & 6.77 & & 40.6 & 78.3 & 88.7 \\
\hline 11 & Non conventional order 1 & $1-(1-F)^{1-n}=(1-n) k_{1-n} t$ & 14.74 & $(\mathrm{n}<1)$ & 25.5 & 50.0 & 59.4 \\
\hline 12 & Non conventional order 2 & $\frac{1}{(1-F)^{n-1}}-1=(n-1) k_{n-1}$ & 11.97 & $(n>1)$ & 34.0 & 57.5 & 65.1 \\
\hline 13 & $\begin{array}{l}\text { Reciprocal powered } \\
\text { time }\end{array}$ & $\left(\frac{\mathbf{1}}{F}-\mathbf{1}\right)=\frac{m}{t^{b}}$ & 6.47 & & 49.1 & 84.9 & 89.6 \\
\hline
\end{tabular}

${ }^{a}$ Parameters of models 1-10 were obtained by linear regression and those of 11-13 were calculated via nonlinear regression. $\mathrm{F}$ denotes fraction of drug released up to time t. $\mathrm{k}_{0}, \mathrm{k}_{\mathrm{f}}, \mathrm{k}_{\mathrm{H}}, \mathrm{p}, \mathrm{k}_{\mathrm{p}}, \mathrm{k}_{1 / 3}, \mathrm{k}_{1 / 2}, \mathrm{k}_{2 / 3}, \mathrm{t}_{\mathrm{d}}, \beta, \mathrm{Z}_{0}, \mathrm{Z}_{0}{ }^{\prime}, \mathrm{q}, \mathrm{q}^{\prime}, \mathrm{n}, \mathrm{k}_{1-\mathrm{n}}, \mathrm{k}_{\mathrm{n}-1}, \mathrm{~m}$ and $\mathrm{b}$ are parameters of the models. $Z$ and $Z^{\prime}$ are probits of fraction of drug released at any time. $Z_{0}$ and $Z_{0}{ }^{\prime}$ are the values of $Z$ and $Z^{\prime}$ when $t=0$ and $t=$ 1, respectively. The relationships between $\mathrm{Z}$ and $\mathrm{Z}$ ' with $\mathrm{F}$ are given by:

$$
F=(2 \pi)^{-\frac{1}{2}} \int_{-\infty}^{Z} \exp \left[\frac{-Z^{2}}{2}\right] d Z \cdot F=(2 \pi)^{-\frac{1}{2}} \int_{-\infty}^{Z^{\prime}} \exp \left[\frac{-Z^{\prime 2}}{2}\right] d Z^{6}
$$

Where $\mathrm{Z}=\left(\mathrm{t}-\mathrm{t}_{50 \%}\right) / \sigma$ and $\mathrm{Z}^{\prime}=\left(\log \mathrm{-}-\log \mathrm{t}_{50 \%}\right) / \sigma^{\prime} . \sigma$ and $\sigma^{\prime}$ are relevant standard deviations $(8,64)$. 


\section{Methods}

The coordinates of each point in the release profile of drug nanoparticles in the original paper were measured carefully and the data was employed in the subsequent kinetic analysis. The accuracy and prediction ability of the models were compared by calculation of absolute percent error (E) for each set as well as overall mean percent error (OE) for all sets are given by equations 1 and 2 :

$$
\begin{aligned}
& E=\frac{100}{N} \sum_{i=1}^{N}\left[\frac{\left|F_{c a l, i}-F_{o b s, i}\right|}{F_{o b s, i}}\right] \\
& O E=\frac{\sum_{i=1}^{106}(E)_{i}}{106}
\end{aligned}
$$

$\mathrm{F}_{\mathrm{cal}, \mathrm{i}}$ and $\mathrm{F}_{\mathrm{obs}, \mathrm{i}}$ denote calculated fraction and observed fraction of drug released at the $i^{\text {th }}$ sample, respectively. The value of $\mathrm{N}$ is the number of data in each set. The number of single figure OEs associated with the models expressed as percentage of total number of sets was also employed to select suitable models.

\section{RESULTS}

The release data of all 106 formulations was fitted to 13 models mentioned in Table 1 . The overall error, number of errors expressed as percentage of total number of sets, NEs, less than 5, 10 and 12\% for the models are seen in the same table. The values of $\mathrm{E}$, squared correlation coefficient $\left(\mathrm{R}^{2}\right)$ and the parameters of reciprocal powered time model for the nanoparticle formulations are given in Table 2.

Table 2: Detail of drug nanoparticles as well as squared correlation coefficients $\left(\mathrm{R}^{2}\right)$, percent error (E) and parameters of

\begin{tabular}{|c|c|c|c|c|c|c|c|c|c|}
\hline \multirow{2}{*}{ No. } & \multirow{2}{*}{ Drug name } & \multirow{2}{*}{ Reference } & \multirow{2}{*}{$N^{a}$} & \multirow{2}{*}{$\begin{array}{l}\text { Nanoparticle } \\
\text { type }\end{array}$} & \multicolumn{5}{|c|}{ Reciprocal powered time model } \\
\hline & & & & & $R^{2}$ & $E$ & $m$ & $b$ & $t_{50 \%}$ (hour) $^{d}$ \\
\hline 1 & 5-fluorouridine & $(12)$ & 6 & NS & 0.993 & 3.3 & 0.663 & 1.185 & 0.7 \\
\hline 2 & 5-fluorouridine & (12) & 7 & NS & 0.985 & 4.8 & 0.562 & 1.442 & 0.7 \\
\hline 3 & 5-fluorouridine & (12) & 7 & NS & 0.965 & 4.3 & 0.942 & 0.625 & 0.9 \\
\hline 4 & 5-fluorouridine & (12) & 7 & NS & 0.983 & 3.7 & 0.776 & 0.747 & 0.7 \\
\hline 5 & 5-fluorouridine & (12) & 7 & NS & 0.995 & 4.3 & 1.401 & 1.094 & 1.4 \\
\hline 6 & 5-fluorouridine & (12) & 7 & NS & 0.991 & 2.2 & 1.154 & 0.589 & 1.3 \\
\hline 7 & 6-coumarin & (13) & 10 & NCP & 0.996 & 4.4 & 6.629 & 0.643 & 18.9 \\
\hline 8 & 6-coumarin & (13) & 10 & NCP & 0.889 & 18.8 & 11.190 & 0.660 & 38.8 \\
\hline 9 & $\begin{array}{l}\text { 9-(methylamino } \\
\text { methyl)anthracene }\end{array}$ & (14) & 10 & $\mathrm{NCP}$ & 0.971 & 4.8 & 1.537 & 1.365 & 1.4 \\
\hline 10 & $\begin{array}{l}\text { 9-(methylamino } \\
\text { methyl)anthracene }\end{array}$ & (14) & 9 & $\mathrm{NCP}$ & 0.988 & 2.6 & 1.392 & 1.084 & 1.4 \\
\hline 11 & $\begin{array}{l}\text { 9-(methylamino } \\
\text { methyl)anthracene }\end{array}$ & (14) & 13 & $\mathrm{NCP}$ & 0.988 & 2.8 & 1.517 & 0.792 & 1.7 \\
\hline 12 & 9-nitrocamptothecin & (15) & 13 & NCP & 0.985 & 9.2 & 30.320 & 0.563 & 428.4 \\
\hline 13 & 9-nitrocamptothecin & (15) & 13 & NCP & 0.982 & 7.8 & 18.770 & 0.551 & 204.7 \\
\hline 14 & 9-nitrocamptothecin & (15) & 13 & NCP & 0.992 & 6.4 & 14.810 & 0.567 & 116 \\
\hline 15 & bovine serum albumin & (16) & 10 & NCP & 0.987 & 5.2 & 7.973 & 0.33 & 539.7 \\
\hline 16 & bovine serum albumin & (16) & 10 & NCP & 0.963 & 8.1 & 4.560 & 0.322 & 111.3 \\
\hline 17 & Ciprofloxacin & (17) & 12 & NCP & 0.993 & 8.9 & 32.680 & 1.206 & 18.0 \\
\hline 18 & Ciprofloxacin $\mathrm{HCl}$ & (18) & 7 & NS & 0.988 & 21 & 23.487 & 0.871 & 37.5 \\
\hline 19 & Ciprofloxacin $\mathrm{HCl}$ & (18) & 7 & NS & 0.999 & 8.5 & 17.210 & 0.86 & 27.4 \\
\hline 20 & Ciprofloxacin $\mathrm{HCl}$ & (18) & 7 & NS & 0.982 & 9.5 & 12.680 & 0.631 & 56 \\
\hline 21 & Ciprofloxacin $\mathrm{HCl}$ & (18) & 7 & NS & 0.989 & 13 & 11.320 & 0.735 & 27.2 \\
\hline 22 & Ciprofloxacin $\mathrm{HCl}$ & (18) & 7 & NS & 0.997 & 7.8 & 17.220 & 0.828 & 31.1 \\
\hline
\end{tabular}
the Reciprocal powered time model. 
Table 2. Continued...

\begin{tabular}{|c|c|c|c|c|c|c|c|c|c|}
\hline 23 & Ciprofloxacin $\mathrm{HCl}$ & (18) & 7 & NS & 0.984 & 12 & 9.843 & 0.618 & 40.5 \\
\hline 24 & Ciprofloxacin $\mathrm{HCl}$ & (18) & 7 & NS & 0.994 & 11 & 10.790 & 0.776 & 21.4 \\
\hline 25 & Cyclosporine & (19) & 6 & NS & 0.991 & 6.7 & 5.065 & 0.798 & 8.6 \\
\hline 26 & Cyclosporine & (19) & 6 & NS & 0.982 & 9.4 & 5.177 & 0.754 & 8.9 \\
\hline 27 & $\begin{array}{l}\text { Dexamethasone } \\
\text { phosphate }\end{array}$ & (20) & 5 & $\mathrm{NCP}$ & 0.993 & 1.6 & 1.548 & 1.211 & 1.4 \\
\hline 28 & Doxorubicin & (21) & 8 & $-{ }^{c}$ & 0.997 & 2.8 & 5.290 & 0.466 & 35.7 \\
\hline 29 & Doxorubicin & $(21)$ & 8 & - & 0.974 & 5.7 & 4.420 & 0.489 & 20.9 \\
\hline 30 & Doxorubicin & (21) & 8 & - & 0.984 & 3.6 & 2.034 & 0.509 & 4.0 \\
\hline 31 & Gonadorelin & (22) & 12 & NCP & 0.947 & 15 & 12.740 & 0.591 & 74.1 \\
\hline 32 & Gonadorelin & $(22)$ & 12 & NCP & 0.939 & 12 & 7.750 & 0.37 & 253.2 \\
\hline 33 & Ibuprofen & (23) & 5 & $\mathrm{NC}$ & 0.993 & 4.5 & 10.066 & 0.866 & 14.4 \\
\hline 34 & Ibuprofen & (23) & 17 & NS & 0.997 & 1.6 & 6.814 & 0.512 & 42.4 \\
\hline 35 & Ibuprofen & (23) & 17 & NS & 0.978 & 5.8 & 13.039 & 0.628 & 59.7 \\
\hline 36 & Ibuprofen & (23) & 17 & NS & 0.890 & 11.2 & 7.202 & 0.414 & 117.8 \\
\hline 37 & Indomethacin & (24) & 5 & NCP & 0.990 & 5.2 & 0.905 & 1.318 & 0.9 \\
\hline 38 & Indomethacin & (24) & 5 & NCP & 0.997 & 3.2 & 1.716 & 1.078 & 1.7 \\
\hline 39 & Insulin & $(25)$ & 9 & $\mathrm{NCP}$ & 0.999 & 1.8 & 53.902 & 1.228 & 25.7 \\
\hline 40 & insulin & (26) & 9 & NS & 0.996 & 6.6 & 4.328 & 1.344 & 2.9 \\
\hline 41 & insulin & (26) & 5 & NS & 0.999 & 2.9 & 0.024 & 3.076 & 0.3 \\
\hline 42 & Methotrexate & (27) & 15 & NCP & 0.992 & 6.1 & 106.609 & 1.326 & 33.8 \\
\hline 43 & Methotrexate & (27) & 15 & NCP & 0.997 & 3.0 & 8.881 & 0.849 & 13.1 \\
\hline 44 & Methotrexate & (27) & 15 & NCP & 0.993 & 8.0 & 12.398 & 0.940 & 14.6 \\
\hline 45 & Methotrexate & (27) & 15 & NCP & 0.977 & 10.0 & 85.297 & 1.367 & 25.9 \\
\hline 46 & Methotrexate & (27) & 15 & NCP & 0.986 & 12.0 & 187.049 & 1.402 & 41.7 \\
\hline 47 & Methotrexate & (27) & 15 & NCP & 0.995 & 7.8 & 9.030 & 0.911 & 11.2 \\
\hline 48 & Methoxyxanthone & (28) & 8 & NCP & 0.984 & 3.5 & 0.546 & 0.729 & 0.4 \\
\hline 49 & Methoxyxanthone & (28) & 8 & $\mathrm{NE}$ & 0.943 & 6.9 & 0.514 & 0.746 & 0.4 \\
\hline 50 & $\begin{array}{l}\text { Methylamino methyl } \\
\text { anthracene }\end{array}$ & (29) & 4 & NCP & 0.976 & 5.2 & 0.907 & 1.004 & 0.9 \\
\hline 51 & $\begin{array}{l}\text { Methylamino methyl } \\
\text { anthracene }\end{array}$ & (29) & 3 & NCP & 0.990 & 3.5 & 0.873 & 1.206 & 0.9 \\
\hline 52 & $\begin{array}{l}\text { Methylamino methyl } \\
\text { anthracene }\end{array}$ & (29) & 7 & NCP & 0.998 & 1.2 & 0.763 & 0.762 & 0.7 \\
\hline 53 & $\begin{array}{l}\text { Methylamino } \\
\text { methyl anthracene }\end{array}$ & (29) & 7 & NCP & 0.997 & 1.4 & 1.009 & 0.725 & 1.0 \\
\hline 54 & $\begin{array}{l}\text { Methylamino methyl } \\
\text { anthracene }\end{array}$ & (29) & 7 & NCP & 0.997 & 1.6 & 0.723 & 0.783 & 0.7 \\
\hline 55 & $\begin{array}{l}\text { Methylamino methyl } \\
\text { anthracene }\end{array}$ & (29) & 6 & NCP & 0.977 & 4.8 & 1.199 & 0.683 & 1.3 \\
\hline 56 & Naltrexone & (30) & 6 & NCP & 0.895 & 3.0 & 1.967 & 0.603 & 3.1 \\
\hline 57 & Naltrexone & $(30)$ & 17 & NCP & 0.650 & 10.5 & 3.559 & 0.431 & 19.0 \\
\hline 58 & Nifedipine & (31) & 14 & $\mathrm{NC}$ & 0.988 & 3.0 & 11.032 & 1.154 & 8.0 \\
\hline 59 & Nifedipine & (31) & 4 & $\mathrm{NC}$ & 0.999 & 0.4 & 2.002 & 2.639 & 1.3 \\
\hline 60 & Norfloxacin & (32) & 10 & NS & 0.971 & 8.6 & 2.694 & 0.999 & 2.7 \\
\hline 61 & Norfloxacin & (32) & 10 & NS & 0.990 & 6.3 & 3.755 & 1.049 & 3.5 \\
\hline 62 & Norfloxacin & $(32)$ & 11 & NS & 0.989 & 6.6 & 5.751 & 0.837 & 8.1 \\
\hline 63 & Norfloxacin & (32) & 11 & NS & 0.995 & 4.4 & 4.296 & 0.918 & 4.9 \\
\hline 64 & Norfloxacin & (32) & 11 & NS & 0.989 & 7.0 & 3.982 & 1.133 & 3.4 \\
\hline 65 & Norfloxacin & (32) & 11 & NS & 0.996 & 4.3 & 5.319 & 0.916 & 6.2 \\
\hline 66 & paclitaxel & (33) & 10 & NCP & 0.419 & 19 & 9.645 & 0.31 & 1497 \\
\hline 67 & paclitaxel & (33) & 10 & NCP & 0.992 & 4.9 & 49.400 & 0.718 & 228.5 \\
\hline
\end{tabular}


Table 2. Continued...

\begin{tabular}{|c|c|c|c|c|c|c|c|c|c|}
\hline 68 & paclitaxel & (33) & 10 & NCP & 0.964 & 6.8 & 20.330 & 0.44 & 939.8 \\
\hline 69 & paclitaxel & (33) & 10 & $\mathrm{NCP}$ & 0.968 & 6.9 & 10.220 & 0.368 & 553.4 \\
\hline 70 & paclitaxel & (33) & 10 & $\mathrm{NCP}$ & 0.961 & 7.5 & 10.953 & 0.374 & 601.9 \\
\hline 71 & paclitaxel & (33) & 10 & NCP & 0.95 & 6.7 & 9.360 & 0.307 & 1458 \\
\hline 72 & $\begin{array}{l}\text { Papaverine } \\
\text { hydrochloride }\end{array}$ & (34) & 17 & NS & 0.979 & 10.6 & 1222.84 & 5.050 & 4.1 \\
\hline 73 & $\begin{array}{l}\text { Papaverine } \\
\text { hydrochloride }\end{array}$ & (34) & 17 & NS & 0.944 & 8.5 & 11.187 & 1.211 & 7.3 \\
\hline 74 & $\begin{array}{l}\text { Papaverine } \\
\text { hydrochloride }\end{array}$ & (34) & 16 & NS & 0.980 & 22.1 & 26.666 & 1.345 & 11.5 \\
\hline 75 & $\begin{array}{l}\text { Papaverine } \\
\text { hydrochloride }\end{array}$ & (34) & 17 & NS & 0.970 & 17.4 & 15.855 & 0.963 & 17.6 \\
\hline 76 & Praziquantel & (35) & 11 & NS & 0.958 & 7.8 & 36.593 & 0.723 & 145.3 \\
\hline 77 & Praziquantel & (35) & 5 & NS & 0.998 & 4.3 & 169.55 & 0.779 & 727.3 \\
\hline 78 & Prednisone & (36) & 5 & NS & 0.989 & 7.1 & 15.069 & 0.705 & 46.9 \\
\hline 79 & Prednisone & (36) & 9 & NS & 0.907 & 13.0 & 6.618 & 0.348 & 228.2 \\
\hline 80 & Procaine & (37) & 6 & NS & 0.992 & 1.2 & 0.099 & 1.161 & 0.1 \\
\hline 81 & progesterone & (38) & 7 & NS & 0.978 & 3.9 & 3.516 & 0.342 & 4.1 \\
\hline 82 & progesterone & (38) & 7 & NS & 0.989 & 2.9 & 3.460 & 0.287 & 75.6 \\
\hline 83 & progesterone & (38) & 7 & NS & 0.999 & 1.3 & 2.037 & 0.58 & 3.4 \\
\hline 84 & progesterone & (38) & 7 & NS & 0.969 & 3.1 & 0.811 & 0.471 & 0.6 \\
\hline 85 & progesterone & (38) & 7 & NS & 0.955 & 2.2 & 0.421 & 0.906 & 0.4 \\
\hline 86 & progesterone & (38) & 5 & NS & 0.994 & 3.19 & 1.987 & 0.498 & 4.0 \\
\hline 87 & progesterone & (38) & 7 & NS & 0.846 & 13 & 1.965 & 0.421 & 5.0 \\
\hline 88 & progesterone & (38) & 7 & NS & 0.965 & 9.5 & 0.580 & 0.535 & 0.4 \\
\hline 89 & propafenone & (39) & 8 & NCP & 0.996 & 1.4 & 9.360 & 0.468 & 118.9 \\
\hline 90 & propafenone & (39) & 8 & NCP & 0.984 & 3.6 & 16.703 & 0.612 & 99.5 \\
\hline 91 & propafenone & (39) & 8 & NCP & 0.977 & 3.5 & 14.405 & 0.615 & 76.5 \\
\hline 92 & propafenone & (39) & 8 & NCP & 0.955 & 6.2 & 13.296 & 0.645 & 55.2 \\
\hline 93 & propafenone & (39) & 8 & NCP & 0.967 & 5 & 19.536 & 0.766 & 48.4 \\
\hline 94 & propafenone & (39) & 8 & NCP & 0.97 & 4.8 & 17.589 & 0.774 & 40.6 \\
\hline 95 & propafenone & (39) & 8 & $\mathrm{NCP}$ & 0.952 & 4.3 & 15.550 & 0.55 & 146.8 \\
\hline 96 & propafenone & (39) & 8 & $\mathrm{NCP}$ & 0.976 & 4.2 & 18.617 & 0.624 & 108.4 \\
\hline 97 & propafenone & (39) & 8 & $\mathrm{NCP}$ & 0.996 & 2.1 & 24.729 & 0.727 & 82.5 \\
\hline 98 & propafenone & (39) & 8 & NCP & 0.996 & 2 & 19.059 & 0.672 & 80.3 \\
\hline 99 & propafenone & (39) & 7 & NCP & 0.984 & 3.1 & 16.716 & 0.762 & 40.3 \\
\hline 100 & Savoxepine & (40) & 12 & NS & 0.978 & 6.7 & 24.414 & 0.506 & 552.5 \\
\hline 101 & Silk peptide & (41) & 6 & NCP & 0.869 & 4.1 & 4.553 & 1.174 & 3.6 \\
\hline 102 & Silk peptide & (41) & 15 & $\mathrm{NCP}$ & 0.865 & 10.0 & 5.328 & 0.549 & 21.1 \\
\hline 103 & Tamoxifen & (42) & 9 & NCP & 0.997 & 3.9 & 8.503 & 0.818 & 13.7 \\
\hline 104 & Tripentone & (43) & 10 & NCP & 0.997 & 23 & 229.90 & 1.391 & 49.9 \\
\hline 105 & Xanthone & (28) & 6 & $\mathrm{NE}$ & 0.924 & 4.0 & 0.422 & 0.550 & 0.2 \\
\hline 106 & Xanthone & (28) & 6 & NCP & 0.752 & 9.2 & 0.681 & 0.380 & 0.4 \\
\hline
\end{tabular}

${ }^{a} \mathrm{~N}$ is number of data in each set. ${ }^{\mathrm{b}} \mathrm{NS}, \mathrm{NCP}, \mathrm{NC}$ and NE stand for nanosphere, nanocapsule, nanocrystal and nonoemulsion.

${ }^{c}$ The type of nanosystem was not specified in the original paper. ${ }^{d} t_{50 \%}$ was calculated by $t_{50 \%}=\mathrm{m}^{1 / b}$. 


\section{DISCUSSION}

Kinetic study of drug release is often useful in obtaining one or two physically meaningful parameters which are employed for comparative purposes and relating the release parameter with important parameters such as bioavailability. Furthermore a kinetic parameter can be used to study the influence of formulation factors on the drug release for optimization as well as control of release. The models having both single figure overall error $(\mathrm{OE})$ and number of single figure OEs higher than $75 \%$ of total number of sets were considered as suitable general models. According to Table 1 the models met this criterion are Weibull (W), reciprocal powered time (RPT) and Wagner's log- probability (LP) models with the OE values of $6.39,6.47$ and 6.77, respectively. From OE point of view our RPT model is comparable with $\mathrm{W}$ but these two are slightly superior to LP model. With respect to number of errors less than 5, 10 and $12 \%$ the RPT model is superior to the other two ones. For example the corresponding NEs less than $10 \%$ for the RPT, W and LP models are 84.9, 80.2 and 78.3 (Table 1). The maximum error not shown in the table associated with the RPT model is $23.0 \%$ which is less than that of $\mathrm{W}$ model $(24.3 \%)$ but higher that of LP model (19.4\%). Regarding the mentioned criteria it can be said that overall proposed RPT model can be considered as a general model for drug release kinetics from nanosystems. The advantage of the model over other models is the fact that from its parameters, $b$ and $\mathrm{m}$, the most meaningful release parameter release half life $\left(\mathrm{t}_{50 \%}\right)$ i.e., time required for $50 \%$ of drug to be released, can be calculated from $t_{50 \%}=\mathrm{m}^{1 / \mathrm{b}}$. This relationship is readily obtained by substitution of 0.5 for $\mathrm{F}, \mathrm{t}_{50 \%}$ for $t$ into the model (equation 13 in Table 1) and subsequent solution for $t_{50 \%}$. The release half life is conversely related to release rate. The parameters of RPT model together with $\mathrm{t}_{50 \%}$ for 106 formulations examined are seen in Table 2.

\section{Theoretical justifications for the best models: Reciprocal powered time model}

The rate of drug release from any solid or semi solid delivery system is usually controlled by dissolution and/or diffusion. Regardless of mechanisms involved in the release, its rate under sink conditions can be expressed by a single general equation as follows:

$$
\frac{d w}{d t}=\frac{D}{h} S C_{s}
$$

$\mathrm{w}$ is amount of drug released up to time $\mathrm{t}$ and $\mathrm{dw} / \mathrm{dt}$ is the rate of release. $\mathrm{D}, \mathrm{S}, \mathrm{C}_{\mathrm{s}}$ and $\mathrm{h}$ are drug molecule diffusion coefficient, effective surface area of drug with release medium, drug solubility in the medium and the length of diffusion path. This equation represents both the Noyes-Whitney law of dissolution (44) applied for dissolution rate limited release as well as the Fick's first law of diffusion used for diffusion rate limited release processes $(45,46)$. In the dissolution process $h$, the thickness of stagnant aqueous layer around drug particle, is constant but $\mathrm{S}$ and sometimes $\mathrm{D}$ are varied during the release process (47). On the other hand in a diffusion rate limited release in addition to $\mathrm{D}, \mathrm{h}$ and sometimes $\mathrm{S}$ are variable during the release process. For a complex system such as nanoparticles equation 3 does not seem to include all other factors influencing the release rate among which penetration rate of liquid into the system; hydration, swelling, relaxation, erosion and dissolution of polymer can be mentioned. The extents of liquid penetration and the polymer contributed properties are directly proportional to $t^{1 / 2}(48)$ and powered of $t$ (49-52), respectively. Thus, these effects are collectively represented as a time dependent variable, $\mathrm{X}$, and equation 3 becomes:

$$
\frac{d w}{d t}=\frac{D}{h} S C_{s} X
$$

Therefore, regardless of release mechanism in order to obtain a general working formula for both dissolution and diffusion rate limited release processes it is assumed that the term $\mathrm{DSX} / \mathrm{h}$ is variable during the release. The integration of equation 4 between time 0 and $t$ as well as 0 and $\infty$ yields: 


$$
\begin{aligned}
& w=C_{s} \int_{-0}^{t}\left(\frac{D S X}{\boldsymbol{h}}\right) d t \\
& w_{\infty}=C_{s} \int_{0}^{\infty}\left(\frac{D S X}{\boldsymbol{h}}\right) d t
\end{aligned}
$$

Where $\mathrm{w}_{\infty}$ is the total amount of drug released in the medium. The amount of drug remaining to be released, $\mathrm{M}$, is given by:

$$
M=w_{\infty}-\mathbf{w}=C_{s} \int_{0}^{\infty}\left(\frac{D S X}{h}\right) d t-C_{s} \int_{0}^{t}\left(\frac{D S X}{h}\right) d t=C_{s} \int_{t}^{\infty}\left(\frac{D S X}{h}\right) d t
$$

Fraction of drug released, $\mathrm{F}$, at any time is calculated by:

$$
F=\frac{w}{w+M}=\frac{C_{s} \int_{0}^{t}\left(\frac{D S X}{\boldsymbol{h}}\right) d t}{C_{s} \int_{0}^{t}\left(\frac{D S X}{\boldsymbol{h}}\right) d t+C_{s} \int_{t}^{\infty}\left(\frac{D S X}{\boldsymbol{h}}\right) d t}=\frac{\int_{0}^{t}\left(\frac{D S X}{\boldsymbol{h}}\right) d t}{\int_{0}^{t}\left(\frac{D S X}{\boldsymbol{h}}\right) d t+\int_{t}^{\infty}\left(\frac{D S X}{\boldsymbol{h}}\right) d t}
$$

Since, the value of $\int_{0}^{t}\left(\frac{D S X}{\boldsymbol{h}}\right) d t$ is increasing with time whereas the opposite is true for $\int_{t}^{\infty}\left(\frac{D S X}{h}\right) d t$, it is reasonable to assume that the respective integrals are expressed by the power terms in the forms of $\alpha \mathrm{t}^{\mathrm{a}}$ and $\alpha^{\prime} \mathrm{t}^{-\mathrm{a}^{\prime}}$. Where $\alpha, \mathrm{a}, \alpha^{\prime}$ and $\mathrm{a}^{\prime}$ are constants. Substitution of the power equations into the far-right side of equation 8 results in:

$$
F=\frac{\alpha \mathrm{t}^{\mathrm{a}}}{\alpha \mathrm{t}^{\mathrm{a}}+\alpha^{t} \mathrm{t}^{-\mathrm{a}^{t}}}=\frac{\alpha \mathrm{t}^{\mathrm{a}+\mathrm{a}^{z}}}{\alpha \mathrm{t}^{\mathrm{a}+\mathrm{a}^{t}}+\alpha^{l}}=\frac{t^{\bar{t}}}{t^{\bar{\partial}}+m}
$$

In which $\mathrm{b}=\mathrm{a}+\mathrm{a}^{\prime}$ and $\mathrm{m}=\alpha^{\prime} / \alpha$. Reciprocating the far right side of equation 9 and subsequent rearrangements would yield the reciprocal powered time model. Equation 9 is similar to previously published model applied for a simpler solid dispersion systems (11). In the derivation leading to that model only the effective surface area of the drug was assumed to be variable and hence the release mechanism was dissolution rate limited solely. The present equation, however, is extended the application of reciprocal powered time model to both dissolution and diffusion rate limited processes and thus is considered to be a general release equation.

\section{The Weibull model}

This is an empirical model which has been widely applied to release data of both rapid and extended release drug delivery systems(53-63). If it is assumed that some of the factors influencing the overall drug release e.g. effective surface area (S) are solely mass dependent, mass of unreleased drug in the medium (8), while the others are considered to be time dependent, thus equation 4 can be written as:

$$
\frac{d w}{d t}=\frac{D}{h} C_{s} k M k^{\prime} t^{p}
$$

Where $\mathrm{kM}=\mathrm{S}$ and $\mathrm{k}^{\prime} \mathrm{t}^{\mathrm{p}}=\mathrm{X}$. According to previously published papers $D \propto t^{-n}$ (47) as well as $\boldsymbol{h} \propto t^{n^{\prime}}(45,46)$, inclusion of theses in to equation 10 and converting the amounts in to fractions in the subsequent equation yields the following relationship: 


$$
\frac{d F}{d t}=k_{b}(1-F) t^{q}
$$

In which $\mathrm{F}=\mathrm{w} / \mathrm{w}_{\infty},(1-\mathrm{F})=\mathrm{M} / \mathrm{w}_{\infty}, \mathrm{w}_{\infty}$ is total amount of drug ultimately released and $\mathrm{q}$ includes $n, n^{\prime}$ and $p$. The value of $k_{b}$ is related to $C_{s}$ and other constants. Rearrangement of equation 11 gives equation 12:

$$
\frac{d F}{(1-F)}=k_{b} t^{q} d t
$$

The integration of equation 12 between times 0 and t yields:

$$
-\ln (1-F)=\frac{k_{b} t^{q+1}}{q+1}
$$

The latter equation can be written as the linear form of Weibull distribution:

$$
\ln [-\ln (1-\mathrm{F})]=\ln \mathrm{k}_{\mathrm{w}}+\beta \ln \mathrm{t}
$$

$$
\text { In which } \mathrm{k}_{\mathrm{w}}=\mathrm{k}_{\mathrm{b}} /(\mathrm{q}+1), \beta=\mathrm{q}+1 \text { and } \mathrm{k}_{\mathrm{w}}=\left(1 / \mathrm{t}_{\mathrm{d}}\right)^{\beta} \text {. }
$$

The derivation here is different from the one provided previously (47) in which constant drug effective surface area and non sink conditions were assumed.

\section{CONCLUSION}

Evaluation of 13 kinetic models for drug release from nanoparticles indicated that three models i.e. the novel reciprocal powered time, Weibull and Wagner's log-probability models were superior to the rest of models in that the errors associated with those were single figures and the number of single figure errors was higher than other models. Among the three mentioned models, the reciprocal powered time model was more suitable than the other two ones considering the accuracy criteria used for comparison. In addition to the mentioned superiority of reciprocal powered time model, from its parameters a fundamental parameter i.e., release half life can be calculated which is a most widely used criterion for comparison of drug release rate. Taking into account complex processes involved in drug release from nanosystems, theoretical justifications for the reciprocal powered time as well as Weibull models were provided. Based on the theoretical justifications, the reciprocal powered time and Weibull models seem to be applicable for any drug release mechanisms involving dissolution, diffusion and mixed dissolution - diffusion rate limited processes.

\section{ACKNOWLEDGMENT}

The authors wish to thank financial support provided by Research Center for Pharmaceutical Nanotechnology, Tabriz University of Medical Sciences, Tabriz,Iran.

\section{REFERENCES}

[1]. Lee, V. H. Nanotechnology: challenging the limit of creativity in targeted drug delivery. Adv Drug Deliv Rev, 56: 1527-1528, 2004.

[2]. Agnihotri, S. A., Mallikarjuna, N. N., and Aminabhavi, T. M. Recent advances on chitosanbased micro- and nanoparticles in drug delivery. J Control Release, 100: 5-28, 2004.

[3]. Emerich, D. F. Nanomedicine--prospective therapeutic and diagnostic applications. Expert Opin Biol Ther, 5: 1-5, 2005.

[4]. Manchester, M. and Singh, P. Virus-based nanoparticles (VNPs): platform technologies for diagnostic imaging. Adv Drug Deliv Rev, 58: 1505-1522, 2006.

[5]. Arayne, M. S., Sultana, N., and Noor, U. S. Fabrication of solid nanoparticles for drug delivery. Pak J Pharm Sci, 20: 251-259, 2007.

[6]. Parveen, S. and Sahoo, S. K. Polymeric nanoparticles for cancer therapy. J Drug Target, 16: 108-123, 2008.

[7]. Sahoo, S. K., Dilnawaz, F., and Krishnakumar, S. Nanotechnology in ocular drug delivery. Drug Discov Today, 13: 144-151, 2008.

[8]. Wagner, J. G. Interpretation of percent dissolved-time plots derived from in vitro testing of conventional tablets and capsules. J Pharm Sci, 58: 1253-1257, 1969.

[9]. Costa, P. and Sousa Lobo, J. M. Modeling and comparison of dissolution profiles. Eur J Pharm Sci, 13: 123-133, 2001.

[10]. Barzegar-Jalali, M. A model for linearizing drug dissolution data. Int J Pharm, 63: R6-R11, 1990.

[11]. Barzegar-Jalali, M. and Dastmalchi, S. Kinetic analysis of chlorpropamide dissolution from 
solid dispersions. Drug Dev Ind Pharm, 33: 6370, 2007.

[12]. Arbos, P., Campanero, M. A., Arangoa, M. A., and Irache, J. M. Nanoparticles with specific bioadhesive properties to circumvent the presystemic degradation of fluorinated pyrimidines. J Control Release, 96: 55-65, 2004.

[13]. Lu, W., Tan, Y. Z., Hu, K. L., and Jiang, X. G. Cationic albumin conjugated pegylated nanoparticle with its transcytosis ability and little toxicity against blood-brain barrier. Int J Pharm, 295: 247-260, 2005.

[14]. Xiong, X. Y., Tam, K. C., and Gan, L. H. Release kinetics of hydrophobic and hydrophilic model drugs from pluronic F127/poly(lactic acid) nanoparticles. J Control Release, 103: 73$82,2005$.

[15]. Derakhshandeh, K., Erfan, M., and Dadashzadeh, S. Encapsulation of 9nitrocamptothecin, a novel anticancer drug, in biodegradable nanoparticles: factorial design, characterization and release kinetics. Eur J Pharm Biopharm, 66: 34-41, 2007.

[16]. Li, Y. P., Zhou, Z. H., Pei, Y. Y., Zhang, X. Y., Gu, Z. H., and Yuan, W. F. PEGylated polycyanoacrylate nanoparticles as salvicine carriers: synthesis, preparation, and in vitro characterization. Acta Pharmacol Sin, 22: 645650, 2001.

[17]. Page-Clisson, M. E., Pinto-Alphandary, H., Ourevitch, M., Andremont, A., and Couvreur, P. Development of ciprofloxacin-loaded nanoparticles: physicochemical study of the drug carrier. J Control Release, 56: 23-32, 1998.

[18]. Dillen, K., Weyenberg, W., Vandervoort, J., and Ludwig, A. The influence of the use of viscosifying agents as dispersion media on the drug release properties from PLGA nanoparticles. Eur J Pharm Biopharm, 58: 539549, 2004.

[19]. Jaiswal, J., Gupta, S. K., and Kreuter, J. Preparation of biodegradable cyclosporine nanoparticles by high-pressure emulsificationsolvent evaporation process. J Control Release, 96: 169-178, 2004.

[20]. Thote, A. J. and Gupta, R. B. Formation of nanoparticles of a hydrophilic drug using supercritical carbon dioxide and microencapsulation for sustained release. Dis Mon, 51: 362-373, 2005.

[21]. Park, K., Lee, G. Y., Kim, Y. S., Yu, M., Park, R. W., Kim, I. S., Kim, S. Y., and Byun, Y. Heparin-deoxycholic acid chemical conjugate as an anticancer drug carrier and its antitumor activity. J Control Release, 114: 300-306, 2006.
[22]. Hu, F. Q., Hong, Y., and Yuan, H. Preparation and characterization of solid lipid nanoparticles containing peptide. Int J Pharm, 273: 29-35, 2004.

[23]. Jiang, B., Hu, L., Gao, C., and Shen, J. Ibuprofen-loaded nanoparticles prepared by a coprecipitation method and their release properties. Int J Pharm, 304: 220-230, 2005.

[24]. Chaw, C. S., Chooi, K. W., Liu, X. M., Tan, C. W., Wang, L., and Yang, Y. Y. Thermally responsive core-shell nanoparticles selfassembled from cholesteryl end-capped and grafted polyacrylamides:; drug incorporation and in vitro release. Biomaterials, 25: 4297-4308, 2004.

[25]. Zhenqing, H., Zhenxi, Z., Chuanxin, Z., and Mei, H. Use of natural plant exudates (Sanguis Draxonis) for sustained oral insulin delivery with dramatic reduction of glycemic effects in diabetic rats. J Control Release, 97: 467-475, 2004.

[26]. Zhang, Q., Shen, Z., and Nagai, T. Prolonged hypoglycemic effect of insulin-loaded polybutylcyanoacrylate nanoparticles after pulmonary administration to normal rats. Int $\mathrm{J}$ Pharm, 218: 75-80, 2001.

[27]. Zhang, Y. and Zhuo, R. X. Synthesis and drug release behavior of poly (trimethylene carbonate)-poly (ethylene glycol)-poly (trimethylene carbonate) nanoparticles. Biomaterials, 26: 2089-2094, 2005.

[28]. Teixeira, M., Alonso, M. J., Pinto, M. M., and Barbosa, C. M. Development and characterization of PLGA nanospheres and nanocapsules containing xanthone and 3methoxyxanthone. Eur J Pharm Biopharm, 59: 491-500, 2005.

[29]. Xiong, X. Y., Tam, K. C., and Gan, L. H. Effect of enzymatic degradation on the release kinetics of model drug from Pluronic F127/poly(lactic acid) nano-particles. J Control Release, 108: 263-270, 2005.

[30]. Yin, W., Akala, E. O., and Taylor, R. E. Design of naltrexone-loaded hydrolyzable crosslinked nanoparticles. Int J Pharm, 244: 9-19, 2002.

[31]. Hecq, J., Deleers, M., Fanara, D., Vranckx, H., and Amighi, K. Preparation and characterization of nanocrystals for solubility and dissolution rate enhancement of nifedipine. Int J Pharm, 299: 167-177, 2005.

[32]. Jeon, H. J., Jeong, Y. I., Jang, M. K., Park, Y. H., and Nah, J. W. Effect of solvent on the preparation of surfactant-free poly(DL-lactideco-glycolide) nanoparticles and norfloxacin 
release characteristics. Int J Pharm, 207: 99-108, 2000.

[33]. Mu, L. and Feng, S. S. A novel controlled release formulation for the anticancer drug paclitaxel (Taxol): PLGA nanoparticles containing vitamin E TPGS. J Control Release, 86: 33-48, 2003.

[34]. Lee, J., Cho, E. C., and Cho, K. Incorporation and release behavior of hydrophobic drug in functionalized poly(D,L-lactide)-blockpoly(ethylene oxide) micelles. J Control Release, 94: 323-335, 2004.

[35]. Mainardes, R. M. and Evangelista, R. C. PLGA nanoparticles containing praziquantel: effect of formulation variables on size distribution. Int $\mathrm{J}$ Pharm, 290: 137-144, 2005.

[36]. Wei, H., Zhang, X., Cheng, C., Cheng, S. X., and Zhuo, R. X. Self-assembled, thermosensitive micelles of a star block copolymer based on PMMA and PNIPAAm for controlled drug delivery. Biomaterials, 28: 99-107, 2007.

[37]. Govender, T., Stolnik, S., Garnett, M. C., Illum, L., and Davis, S. S. PLGA nanoparticles prepared by nanoprecipitation: drug loading and release studies of a water soluble drug. J Control Release, 57: 171-185, 1999.

[38]. Matsumoto, J., Nakada, Y., Sakurai, K., Nakamura, T., and Takahashi, Y. Preparation of nanoparticles consisted of poly(L-lactide)poly(ethylene glycol)-poly(L-lactide) and their evaluation in vitro. Int J Pharm, 185: 93-101, 1999.

[39]. Sant, S., Nadeau, V., and Hildgen, P. Effect of porosity on the release kinetics of propafenoneloaded PEG-g-PLA nanoparticles. J Control Release, 107: 203-214, 2005.

[40]. Leroux, J. C., Allemann, E., De Jaeghere, F., Doelker, E., and Gurny, R. Biodegradable nanoparticles from sustained release formulations to improved site specific drug delivery. J Control Release, 39: 339-350, 1996.

[41]. Hu, Y., Jiang, X., Ding, Y., Ge, H., Yuan, Y., and Yang, C. Synthesis and characterization of chitosan-poly(acrylic acid) nanoparticles. Biomaterials, 23: 3193-3201, 2002.

[42]. Hu, F. X., Neoh, K. G., and Kang, E. T. Synthesis and in vitro anti-cancer evaluation of tamoxifen-loaded magnetite/PLLA composite nanoparticles. Biomaterials, 27: 5725-5733, 2006.

[43]. Malzert-Freon, A., Vrignaud, S., Saulnier, P., Lisowski, V., Benoit, J. P., and Rault, S. Formulation of sustained release nanoparticles loaded with a tripentone, a new anticancer agent. Int J Pharm, 320: 157-164, 2006.
[44]. Noyes, A. and itney, W. The rate of solution of solid substances in their own solutions. J Am Chem Soc, 19: 934, 1897.

[45]. Higuchi, T. Rate of release of medicaments from ointment bases containing drugs in suspension. J Pharm Sci, 50: 874-875, 1961.

[46]. Higuchi, T. Mechanism of sustained - action medication. Theoretical analysis of release of solid drugs dispersed in solid matrices. J Pharm Sci, 52: 1145-1149, 1963.

[47]. Macheras, P. and Dokoumetzidis, A. On the heterogeneity of drug dissolution and release. Pharm Res, 17: 108-112, 2000.

[48]. Washburn, E. W. The dynamics of capillary flow. PHYSICAL REVIEW, 17: 273-283, 1921.

[49]. Peppas, N. A. Analysis of Fickian and nonFickian drug release from polymers. Pharm Acta Helv, 60: 110-111, 1985.

[50]. Ritger, P. L. and Peppas, N. A. A simple equation for description of solute release. I. Fickian and anomalous release from swellable devices. J Control Release, 5: 37-42, 1987.

[51]. Harland, R. S., Gazzaniga, A., Sangalli, M. E., Colombo, P., and Peppas, N. A. Drug/polymer matrix swelling and dissolution. Pharm Res, 5: 488-494, 1988.

[52]. Peppas, N. A. and Sahlin, J. J. A simple equation for the description of solute release. III. Coupling of diffusion and relaxation. Int J Pharm, 57: 169$172,1989$.

[53]. Langenbucher, F. Linearization of dissolution rate curves by the Weibull distribution. J Pharm Pharmacol, 24: 979-981, 1972.

[54]. Lin, S. Y. and Kawashima, Y. Drug release from tablets containing cellulose acetate phthalate as an additive or enteric-coating material. Pharm Res, 4: 70-74, 1987.

[55]. Chen, D. B., Yang, T. Z., Lu, W. L., and Zhang, Q. In vitro and in vivo study of two types of long-circulating solid lipid nanoparticles containing paclitaxel. Chem Pharm Bull (Tokyo), 49: 1444-1447, 2001.

[56]. Morales, M. E., Gallardo, L., V, Calpena, A. C., Domenech, J., and Ruiz, M. A. Comparative study of morphine diffusion from sustained release polymeric suspensions. J Control Release, 95: 75-81, 2004.

[57]. Venkateswarlu, V. and Manjunath, K. Preparation, characterization and in vitro release kinetics of clozapine solid lipid nanoparticles. J Control Release, 95: 627-638, 2004.

[58]. Zeo, U., Tarabukina, E., and Budtova, T. Kinetics of shear-induced gel deswelling/solvent release. J Control Release, 108: 73-83, 2005. 
[59]. Pattarino, F., Giovannelli, L., and Bellomi, S. Effect of poloxamers on nifedipine microparticles prepared by Hot Air Coating technique. Eur J Pharm Biopharm, 2006.

[60]. Raffin, R. P., Colome, L. M., Pohlmann, A. R., and Guterres, S. S. Preparation, characterization, and in vivo anti-ulcer evaluation of pantoprazole-loaded microparticles. Eur J Pharm Biopharm, 63: 198-204, 2006.

[61]. Papadopoulou, V., Kosmidis, K., Vlachou, M., and Macheras, P. On the use of the Weibull function for the discernment of drug release mechanisms. Int J Pharm, 309: 44-50, 2006.

[62]. Adibkia, K., Siahi Shadbad, M. R., Nokhodchi, A., Javadzedeh, A., Barzegar-Jalali, M., Barar, J., Mohammadi, G., and Omidi, Y. Piroxicam nanoparticles for ocular delivery: physicochemical characterization and implementation in endotoxin-induced uveitis. J Drug Target, 15: 407-416, 2007.

[63]. Liu, J., Gong, T., Wang, C., Zhong, Z., and Zhang, Z. Solid lipid nanoparticles loaded with insulin by sodium cholate-phosphatidylcholinebased mixed micelles: preparation and characterization. Int $\mathrm{J}$ Pharm, 340: 153-162, 2007.

[64]. Lippmann, I. Curve fitting of dissolution data from solid dosage form with the assistance of a digital computer. In L. J. Leeson and J. T. Corstensen (eds.), Dissolution technology, Washington D.C., 1974. 